\title{
Critical illness associated with 2013-2014 influenza A (H1N1): Postpandemic characteristics, presentation and outcomes
}

\author{
Jonathan Wiesen, Dhruv Joshi, Jorge A. Guzman, Abhijit Duggal
}

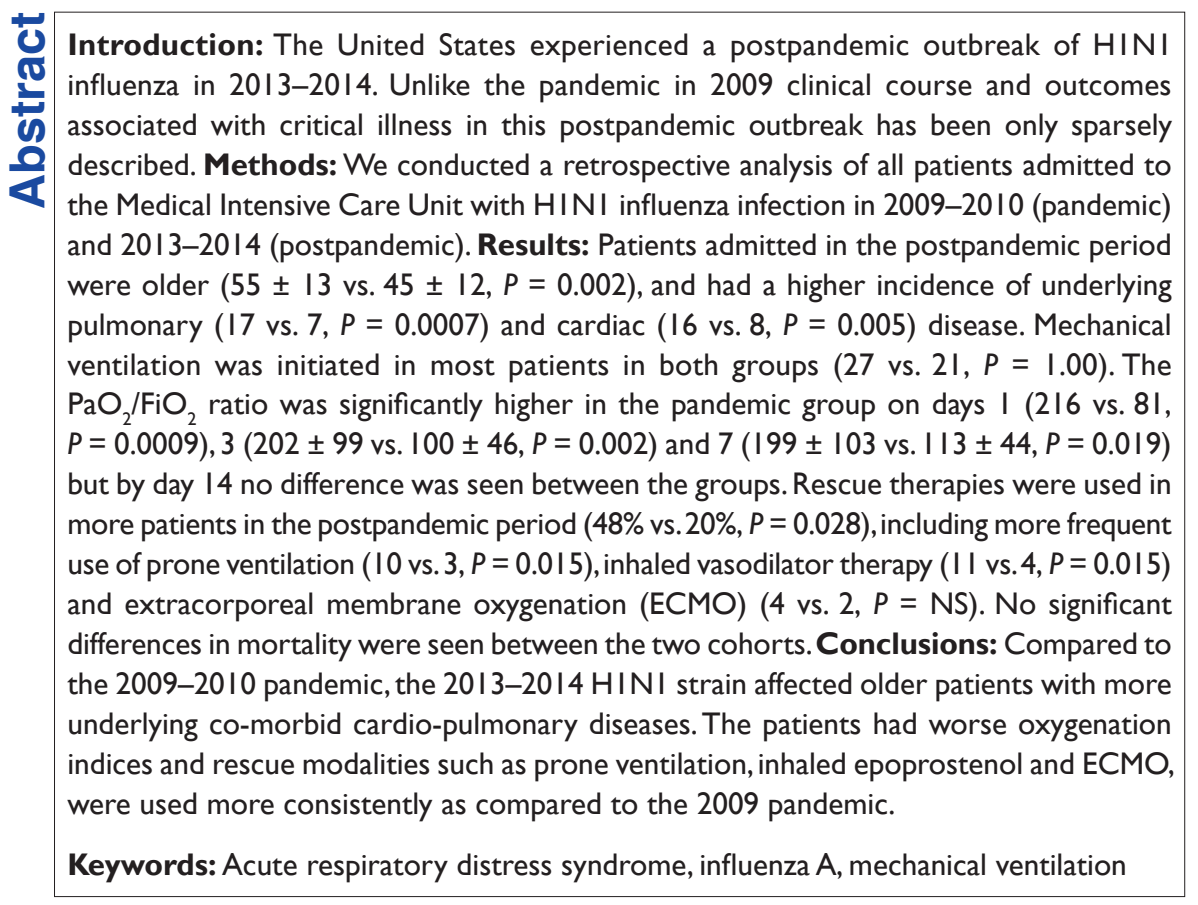

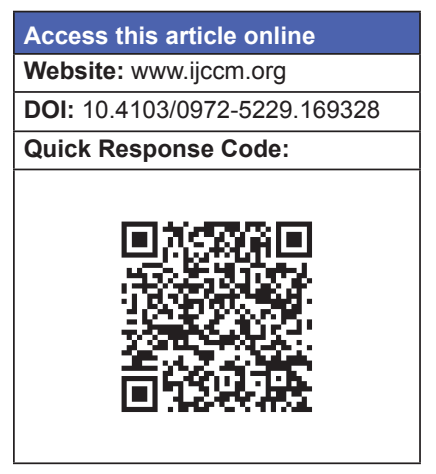

\section{Introduction}

The 2009 influenza A (H1N1) pandemic highlighted the differences of this strain from seasonal influenza, due to its higher incidence and virulence in younger individuals, obese patients, and pregnant women. ${ }^{[1,2]}$ Affected patients developed rapidly progressive hypoxemia requiring significant ventilatory support ${ }^{[1-4]}$ and the frequent utilization of extracorporeal membrane oxygenation (ECMO) as a rescue therapy. ${ }^{[3,4]}$ Since the first reports of the pandemic, 3 subsequent waves were

From:

Department of Pulmonary Critical Care, Cleveland Clinic, Respiratory Institute, Cleveland, Ohio, USA

\section{Correspondence:}

Dr. Abhijit Duggal, 9500 Euclid Avenue, G6-156, Cleveland, OH 44195, USA. E-mail: duggala2@ccf.org documented throughout the world, and similar clinical presentation, case mix, and fatalities were reported globally. ${ }^{[5,6]}$

North America saw a predominance of the H1N1 strain of the influenza virus during the winter season of 2013-2014. ${ }^{[7]}$ The Center for Disease Control noted a

This is an open access article distributed under the terms of the Creative Commons Attribution-NonCommercial-ShareAlike 3.0 License, which allows others to remix, tweak, and build upon the work non-commercially, as long as the author is credited and the new creations are licensed under the identical terms.

For reprints contact: reprints@ medknow.com

How to cite this article: Wiesen J, Joshi D, Guzman JA, Duggal A. Critical illness associated with 2013-2014 influenza A (H1N1): Postpandemic characteristics, presentation and outcomes. Indian J Crit Care Med 2015;19:636-41. 
heavy burden of predominantly H1N1 influenza viral infection in all 50 states in the United States. ${ }^{[8]}$ Unlike the pandemic in 2009 clinical course and outcomes of critically ill patients infected with the 2013-2014 strain of H1N1 influenza virus has been only sparsely described..$^{[9,10]}$ We report the experience with critical illness associated with the 2013-2014 H1N1 outbreak at a quaternary referral institution. We also report the differences in the baseline characteristics, presentation, and the management of these patients compared to the 2009 pandemic and comment on any consequent differences in outcomes between the groups.

\section{Methods}

\section{Patients}

We included all patients with confirmed influenza A/H1N1 infection who were treated in our Medical Intensive Care Unit (MICU) between April 2009 and April 2010 (pandemic group), and then again from November 2013 to February 2014 (postpandemic group). We defined a case as being confirmed if the influenza A virus rapid antigen testing, Reverse transcription polymerase chain reaction, or viral culture from nasopharyngeal swabs, tracheal aspirates, or bronchoalveolar lavage (BAL) specimens was positive.

\section{Data collection}

We recorded demographic and clinical data including age, gender, height, weight, body mass index, symptoms on presentation to the emergency department, medical history, vital signs, presence of vasopressors, laboratory values, ventilator settings and respiratory parameters, Sequential Organ Failure Assessment (SOFA) scores on admission to the MICU, duration of mechanical ventilation (MV), duration of ICU and hospital stay, mortality, and the use of rescue therapies (namely inhaled nitric oxide or prostacyclin, prone position ventilation, high-frequency oscillatory ventilation, and ECMO).

We also recorded specific data in regards to the MV and respiratory parameters in these patients. We documented: (1) Mode of ventilation: The mode of ventilation that was used for the longest time for a given day; (2) $\mathrm{PaO}_{2} / \mathrm{FiO}_{2}$ : Worst daily ratios were recorded; (3) positive end expiratory pressure (PEEP): The value corresponding to the highest PEEP for the day was recorded; and (4) tidal volume $(\mathrm{Vt})$ : The largest daily volume was recorded. Respiratory data was captured on the $1^{\text {st }}$ day of intubation (day 1 ), and then on subsequent days 3, 7 and 14 of MV. We also collected ICU-specific interventions such as the use of vasopressors and the need for continuous dialysis on these days.

\section{Statistical analysis}

Descriptive statistics is reported as frequency analysis (percentages) for categorical variables and means (standard deviation), or medians (interquartile range) for continuous variables. We used a Student's $t$-test, or Wilcoxon's rank sum test as appropriate for continuous variables, and Chi-square test or Fisher's exact test for discrete variables. Confidence intervals and $P$ values reflect a two-tailed $\alpha$ level of 0.05 . Statistical analysis was performed using SAS version 9.1 (SAS Institute, Cary, NC).

\section{Results}

\section{Patient characteristics}

A total of 62 patients were enrolled during the two study periods. 35 patients were admitted to the MICU in 2009-2010 (Pandemic group), and 27 were admitted in 2013-2014 (postpandemic group) [Table 1]. Patients in the postpandemic were older ( $55 \pm 13$ vs. $45 \pm 12$ years, $P=0.002)$, and had a higher prevalence of co-morbid pulmonary and cardiac conditions.

\begin{tabular}{|c|c|c|c|}
\hline & 2009-2010 & $2013-2014$ & $\mathbf{P}$ \\
\hline Age, mean (SD), years & $45 \pm 12$ & $55 \pm 13$ & 0.002 \\
\hline Female sex & $15(43)$ & $13(48)$ & 0.68 \\
\hline $\mathrm{BMI}\left(\mathrm{kg} / \mathrm{m}^{2}\right)$ & $33(28-4 I)$ & $36(27-4 I)$ & 0.76 \\
\hline \multicolumn{4}{|l|}{ Comorbidities } \\
\hline Chronic lung disease & $7(20)$ & $17(63)$ & $<0.001$ \\
\hline Cardiac disease & $7(20)$ & $16(60)$ & 0.002 \\
\hline Chronic renal insufficiency & $5(14)$ & $3(I I)$ & 0.99 \\
\hline Tobacco use & $17(49)$ & $8(30)$ & 0.13 \\
\hline Neurological disease & $3(9)$ & $10(37)$ & 0.01 \\
\hline \multicolumn{4}{|l|}{ Severity of disease at admission } \\
\hline Vasopressors on admission & $6(17)$ & $10(37)$ & 0.07 \\
\hline AKI need for dialysis & $19(54)$ & $8(30)$ & 0.05 \\
\hline SOFA score, day I & $8.7(3.7)$ & $8.4(4.3)$ & 0.81 \\
\hline \multicolumn{4}{|l|}{$\begin{array}{l}\text { Admission vital signs and } \\
\text { laboratory values }\end{array}$} \\
\hline $\mathrm{SBP}(\mathrm{mm} \mathrm{Hg})$ & $130 \pm 26$ & $122 \pm 27$ & 0.27 \\
\hline Diastolic pressure $(\mathrm{mm} \mathrm{Hg})$ & $69(64-78)$ & 7II (57-86) & 0.88 \\
\hline Temperature $\left({ }^{\circ} \mathrm{C}\right)$ & $37.7 \pm 1.4$ & $37.7 \pm I .1$ & 0.87 \\
\hline RR (breath/min) & $24(20-27)$ & $24(20-29)$ & 0.57 \\
\hline HR (beats/min) & $105 \pm 24$ & $112 \pm 29$ & 0.29 \\
\hline WBC (k/uL) & $9.8(3.9-15)$ & $9.8(6.9-11.9)$ & 0.84 \\
\hline Platelets (k/uL) & $163(108-252)$ & $179(|33-27|)$ & 0.34 \\
\hline Creatinine (mg/dL) & $\mathrm{I} .3(0.8-2.7)$ & I (0.7-I.7) & 0.11 \\
\hline Bilirubin (mg/dL) & $0.4(0.2-0.8)$ & $0.4(0.3-0.5)$ & 0.60 \\
\hline CK (U/L) & $274(94-\mid 488)$ & $169(90-520)$ & 0.16 \\
\hline
\end{tabular}




\section{Initial presentation}

There was no difference in the initial laboratory studies between the groups [Table 1]. The rate of respiratory failure at the time of presentation to the ICU was similar in both the cohorts $(78 \%$ and $82 \%$ for Groups $A$ and $B$, respectively, $P=$ NS). More patients in the postpandemic group required vasopressors on admission ( $37 \%$ vs. $14 \%, P=0.07)$, and more patients in the pandemic group had acute kidney injury (AKI) $(54 \%$ vs. $30 \%, P=0.05)$. The SOFA scores on admission were comparable (8.7 and 8.4, respectively, $P=$ NS). Similar numbers of patients in both groups required invasive and noninvasive positive pressure ventilation [Table 2].

A nasopharyngeal swab was the diagnostic modality used most often to diagnose Influenza in the postpandemic group (23 patients). The other patients were diagnosed by BAL $(n=2)$ or a sputum sample $(n=2)$. Thirty percent of patients had at least one false negative test, including one patient who had a negative BAL but a positive nasopharyngeal swab. The data for Group A were unavailable.

Table 2: Ventilatory characteristics for critically ill patients (pandemic compared to postpandemic Influenza A/H IN I outbreak)

\begin{tabular}{|c|c|c|c|}
\hline & $\begin{array}{c}2009-2010 \\
(n=35) \\
n(\%)\end{array}$ & $\begin{array}{c}2013-2014 \\
(n=27) \\
n(\%)\end{array}$ & P-value \\
\hline Mechanical ventilation at admission & $27(78)$ & $22(82)$ & 0.78 \\
\hline Invasive & $25(93)$ & $16(73)$ & 0.67 \\
\hline Noninvasive & $2(7)$ & $6(27)$ & 0.11 \\
\hline Failure of noninvasive & I (50) & $2(33)$ & \\
\hline Ever ventilated & $28(80)$ & $25(93)$ & 0.17 \\
\hline Patients requiring rescue therapies & $7(20)$ & $13(48)$ & 0.028 \\
\hline \multicolumn{4}{|l|}{ Rescue therapies for hypoxemia } \\
\hline Nitric oxide or inhaled epoprostenol & $4(\mathrm{II})$ & II (4I) & 0.01 \\
\hline Prone ventilation & $3(9)$ & $10(37)$ & 0.01 \\
\hline ECMO & $2(6)$ & $3(\mathrm{II})$ & \\
\hline APRV & $3(9)$ & $4(15)$ & \\
\hline HFOV & I (3) & - & \\
\hline Liberation from ventilation (60 days) & $16(57)$ & $14(56)$ & I \\
\hline
\end{tabular}

Values expressed as number (percentages); ECMO: Extracorporeal membrane oxygenation; HFOV: High-frequency oscillatory ventilation; APRV: Airway pressure release ventilation

\section{Acute respiratory distress syndrome and mechanical ventilation}

Acute respiratory distress syndrome (ARDS) was common on presentation in both groups, and most patients required invasive $\mathrm{MV}$ over the course of their hospitalization. Although the Vt and PEEP in both groups were similar, the $\mathrm{PaO}_{2} / \mathrm{FIO}_{2}$ ratio was significantly worse in the postpandemic group over the $1^{\text {st }}$ week of MV [Table 3]. Patients in the postpandemic group had higher PEEP requirements on day 7 and 14 (16 vs. 10, and 17 vs. $10 \mathrm{~cm} \mathrm{H}_{2} \mathrm{O}, P<0.05$ and NS, respectively). Nonconventional therapies for severe hypoxia were used more frequently in the postpandemic group on days 3 and 7. Overall, more patients in the postpandemic group required nonconventional therapies $(48 \%$ vs. $20 \%, P=0.028)$ and more rescue therapies were utilized including more frequent use of prone ventilation (10 vs. $3, P=0.015)$, inhaled vasodilator therapy (11 vs. 4 , $P=0.015)$ and ECMO (4 vs. 2, $P=0.39$ ) [Tables 2 and 4 ]. One patient in the postpandemic group underwent bilateral lung transplantation after demonstrating an inability to be liberated from ECMO. All patients (with one exception in the pandemic group) in both groups were treated with oseltamivir. Eighteen patients in the pandemic group and 3 patients in the postpandemic group received double dose therapy (150 $\mathrm{mg}$ twice a day).

Outcomes between the two groups were similar although the postpandemic group tended to have a longer ICU and hospital length of stay (18 vs. 13 and 24 vs. 17 days, $P=$ NS for both, respectively) and higher mortality ( $41 \%$ vs. $26 \%, P=0.28)$ [Table 5].

\section{Discussion}

Although other countries experienced earlier postpandemic waves of H1N1 influenza virus infection, the United States did not see a resurgence of this strain until the winter of 2013-2014. Reports of patients with H1N1 infection in $2009^{[1-4]}$ noted a proclivity for severe infection in healthy patients with younger age and obesity. The 2013 cohort in our study still had a significant

Table 3: Ventilatory and oxygenation parameters on days I, 3, 7, and I4 of mechanical ventilation (pandemic compared to postpandemic Influenza A/HIN I outbreak)

\begin{tabular}{|c|c|c|c|c|c|c|c|c|}
\hline & \multicolumn{8}{|c|}{ Mechanical ventilation parameters and oxygenation indices } \\
\hline & \multicolumn{2}{|c|}{ Day I } & \multicolumn{2}{|c|}{ Day 3} & \multicolumn{2}{|c|}{ Day 7} & \multicolumn{2}{|c|}{ Day 14} \\
\hline & 2009 & 2014 & 2009 & 2014 & 2009 & 2014 & 2009 & 2014 \\
\hline Mechanically ventilated patients & $27(77)$ & $22(82)$ & $25(86)$ & $18(86)$ & $23(92)$ & $15(84)$ & II (85) & $12(86)$ \\
\hline $\mathrm{PaO}_{2} / \mathrm{FiO}_{2}$ & $167(92-320)$ & $66 *(56-87)$ & $170(114-288)$ & $98 *(65-121)$ & $184(105-248)$ & $95 *(77-152)$ & $146(84-178)$ & $15 \mid(133-167)$ \\
\hline $\operatorname{PEEP}\left(\mathrm{cm}^{2} \mathrm{H}_{2} \mathrm{O}\right)$ & $18(12-20)$ & $18(8-20)$ & $13(5-18)$ & $15(8-18)$ & $10(5-18)$ & $16 *(10-20)$ & $10(8-12)$ & $17(6-21)$ \\
\hline $\mathrm{Vt}(\mathrm{ml} / \mathrm{kg})$ & $8 \pm 1.6$ & $7.2 \pm 1.4$ & $8.3(7-9.6)$ & $8(7-8)$ & $8(6.8-8.6)$ & $7.8(7.7-8)$ & $7.7 \pm 1.8$ & $7.5 \pm 1.1$ \\
\hline
\end{tabular}

Values expressed as number (percentages). SD: Standard deviation; IQR: Interquartile range; PEEP: Positive end expiratory pressure; Vt: Tidal volume 
Table 4: Clinical course of patients in the ICU (pandemic compared to postpandemic Influenza A/HINI outbreak)

\begin{tabular}{|c|c|c|c|c|c|c|c|c|}
\hline & \multicolumn{2}{|c|}{ Day I n (\%) } & \multicolumn{2}{|c|}{ Day 3 n (\%) } & \multicolumn{2}{|c|}{ Day 7 n (\%) } & \multicolumn{2}{|c|}{ Day 14 n (\%) } \\
\hline & 2009 & 2014 & 2009 & 2014 & 2009 & 2014 & 2009 & 2014 \\
\hline Patients in ICU & 35 & 27 & 29 & 21 & 25 & 18 & 13 & 14 \\
\hline Patients requiring dialysis & - & - & $7(24)$ & $2(10)$ & $7(28)$ & $4(22)$ & $8(62)$ & $3(22)$ \\
\hline Patients requiring vasopressors & $6(17)$ & $10(37)$ & $6(21)$ & $9(43)$ & $5(20)$ & $7(39)$ & $2(15)$ & $2(14)$ \\
\hline Mechanically ventilated patients & $27(77)$ & $22(82)$ & $25(86)$ & $18(86)$ & $23(92)$ & $15(84)$ & II (85) & $12(86)$ \\
\hline Use of rescue therapy* & $5(19)$ & $5(23)$ & $4(16)$ & $8(45)$ & $3(13)$ & $8(53)$ & $4(34)$ & $4(34)$ \\
\hline Mortality & & & I (3) & $3(\mathrm{II})$ & $2(6)$ & $5(19)$ & $5(14)$ & $7(26)$ \\
\hline
\end{tabular}

The numbers here reflect the percentage based on the patients in ICU for all the variables except rescue therapies which are based on the number of patients who are mechanically ventilate. ICU: Intensive Care Unit

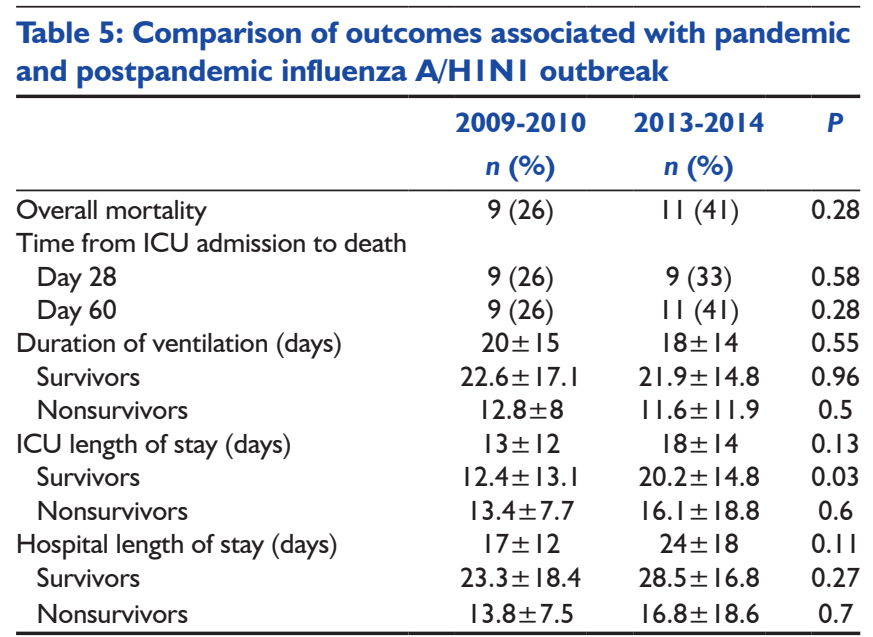

Values expressed as number (percentages). SD: Standard deviation; IQR: Interquartile range; ICU: Intensive Care Unit

number of obese patients, but there were significant differences from previously reported literature. The 2013-2014 outbreak affected older individuals with chronic medical conditions when compared to the 2009 pandemic cohort. Despite a statistically significant difference in age of the two cohorts, it was striking that both these disease outbreaks did not affect geriatric populations ( $>65$ years of age), preexisting immunity from previous outbreaks in the 1950's and 1960's might explain this finding. ${ }^{[11]}$ These features are more reminiscent of populations effected by seasonal influenza rather than the 2009 H1N1 outbreak. This might be due to the development of immunity in younger individuals as a result of exposure to the H1N1 strain in 2009. Moreover, a lower rate of vaccination during the 2013-2014 season in at-risk patients might explain the shift in the age of the effected population. ${ }^{[10]}$

Our data also suggests that available Influenza diagnostic tests are imperfect. Our false negative rate of $30 \%$ in the postpandemic group is similar to other published data on this topic, ${ }^{[12]}$ and highlights the importance of continued diagnostic evaluation in situations of high clinical suspicion of influenza infection, even in the face of one or more negative results.
Acute severe hypoxic respiratory failure necessitating positive pressure ventilation was a cardinal feature of severe H1N1 infection in patients admitted to intensive care units in both 2009 and 2013, ${ }^{[1-4,10]}$ and was common in both groups. However, patients in the postpandemic group tended to be more hypoxic, as evidenced by lower $\mathrm{PaO}_{2} / \mathrm{FIO}_{2}$ ratios and higher PEEP requirements. Rescue therapies for refractory hypoxemia were used in more patients in the postpandemic group, particularly on days 3 and 7 of the ICU stay. Despite worsening hypoxemia in this cohort, the mortality was similar to the pandemic cohort. The more frequent use of nonconventional therapies such as prone ventilation, inhaled vasodilators and ECMO in the postpandemic period likely reflects both the severity of hypoxemia, as well as the impact of newer studies changing clinical practice in critical illness since the 2009 pandemic. ${ }^{[13-15]}$ Patients who required nonconventional therapies for refractory hypoxemia in the postpandemic period had good outcomes. Three of the 4 patients placed on ECMO and $6 / 10$ patients who were ventilated in the prone position survived.

Abnormalities in liver function testing, noted in both groups, have been reported in association with H1N1 infection, with the hypothesis that the pandemic strain of Influenza has specific hepatotropic characteristics. ${ }^{[16]}$ Influenza A infections have been associated with the development of AKI. ${ }^{[17]}$ Although there is no clear evidence of the underlying mechanism, previous studies have shown an association of myoglobinuria and rhabdomyolysis with Influenza A infections. ${ }^{[17]}$ High rates of AKI complicated the 2009 H1N1 pandemic, and the rates in our cohort are similar to previously reported numbers. ${ }^{[18]}$ AKI was prevalent in both the groups in our study, but the rates were significantly lower in the 2013-2014 cohort. This is likely a reflection of more aggressive initial volume resuscitation due to the implementation of sepsis protocol and appropriate renal-protective doses of medications as a result of an antimicrobial stewardship program that were implemented over the last few years. 
The mortality in both cohorts was high, although similar to reports of severe H1N1 Influenza infection in 2009 both globally $^{[1-4]}$ as well as in our institution. ${ }^{[19]}$ This is most likely a function of a selection bias due to the quaternary nature of our institute and a high rate of referral for severe ARDS. The mortality rate of patients in our study was similar to that reported from previous observational cohorts and pragmatic trials in severe ARDS. ${ }^{[20-22]}$

Lung transplantation, although previously reported, is an uncommon rescue intervention in cases of severe ARDS. ${ }^{[23]}$ It was utilized in one patient in our study who could not be liberated from ECMO. Its utility as a salvage therapy for ARDS after prolonged ECMO requires further clarification and study.

There are a number of limitations to our study. As a retrospective chart review, information culled for study purposes was at times incomplete. In addition, we understand the risk of selection bias due to the fact that our patient cohort represents only patients admitted to the intensive care unit of our specific tertiary referral center and may not be representative of the entire population. The small sample size further limits definitive statements regarding the generalizability of our findings. Moreover, it is challenging to distinguish whether observed differences were secondary to substantive differences between the cohorts or the result of clinical practice changes. Despite these limitations, the authors believe that the this study provides a meaningful and intuitive comparison between the two cohorts.

\section{Conclusion}

Our data indicate that there were clear distinctions in the "at risk" population during the two influenza A (H1N1) outbreaks. The 2009 pandemic clearly affected younger, healthier individuals, whereas the 2013-2014 outbreak behaved like seasonal influenza with a higher incidence in an older and more chronically ill population. Our data validate concerns that virulent influenza strains can have a significant burden on critical care resources and clinicians must maintain a high index of suspicion during influenza season, even in the face of negative diagnostic evaluations. Although there was a high rate of severe hypoxemic respiratory failure in both groups, recent studies have clearly changed practice patterns and have influenced the utilization of unconventional rescue therapies more often than in the pandemic of 2009.

\section{Financial support and sponsorship Nil.}

\section{Conflicts of interest}

There are no conflicts of interest.

\section{References}

1. Jain S, Kamimoto L, Bramley AM, Schmitz AM, Benoit SR, Louie J, et al. Hospitalized patients with 2009 H1N1 influenza in the United States, April-June 2009. N Engl J Med 2009;361:1935-44.

2. ANZIC Influenza Investigators, Webb SA, Pettilä V, Seppelt I, Bellomo R, Bailey M, et al. Critical care services and 2009 H1N1 influenza in Australia and New Zealand. N Engl J Med 2009;361:1925-34.

3. Australia and New Zealand Extracorporeal Membrane Oxygenation (ANZ ECMO) Influenza Investigators, Davies A, Jones D, Bailey M, Beca J, Bellomo R, et al. Extracorporeal membrane oxygenation for 2009 influenza A (H1N1) acute respiratory distress syndrome. JAMA 2009;302:1888-95.

4. Chowell G, Bertozzi SM, Colchero MA, Lopez-Gatell H, Alpuche-Aranda C, Hernandez M, et al. Severe respiratory disease concurrent with the circulation of H1N1 influenza. N Engl J Med 2009;361:674-9.

5. ANZIC Influenza Investigators, Webb SA, Aubron C, Bailey M, Bellomo R, Howe B, et al. Critical care services and the H1N1 (2009) influenza epidemic in Australia and New Zealand in 2010: The impact of the second winter epidemic. Crit Care 2011;15:R143.

6. Martin-Loeches I, Díaz E, Vidaur L, Torres A, Laborda C, Granada R, et al. Pandemic and post-pandemic influenza A (H1N1) infection in critically ill patients. Crit Care 2011;15:R286.

7. Ayscue P, Murray E, Uyeki T, Zipprich J, Harriman K, Salibay C, et al. Influenza-associated intensive-care unit admissions and deaths - California, September 29, 2013-January 18, 2014 MMWR Morb Mortal Wkly Rep 2014;63:143-7.

8. Arriola CS, Brammer L, Epperson S, Blanton L, Kniss K, Mustaquim D, et al. Update: Influenza activity - United States, September 29, 2013-February 8, 2014. MMWR Morb Mortal Wkly Rep 2014;63:148-54.

9. Napolitano LM, Angus DC, Uyeki TM. Critically ill patients with influenza A (H1N1) pdm09 virus infection in 2014. JAMA 2014;311:1289-90.

10. Catania J, Que LG, Govert JA, Hollingsworth JW, Wolfe CR. High intensive care unit admission rate for 2013-2014 influenza is associated with a low rate of vaccination. Am J Respir Crit Care Med 2014;189:485-7.

11. Skountzou I, Koutsonanos DG, Kim JH, Powers R, Satyabhama L, Masseoud F, et al. Immunity to pre-1950 H1N1 influenza viruses confers cross-protection against the pandemic swine-origin 2009 A (H1N1) influenza virus. J Immunol 2010;185:1642-9.

12. Chartrand C, Leeflang MM, Minion J, Brewer T, Pai M. Accuracy of rapid influenza diagnostic tests: A meta-analysis. Ann Intern Med 2012;156:500-11.

13. Guérin C, Reignier J, Richard JC, Beuret P, Gacouin A, Boulain T, et al. Prone positioning in severe acute respiratory distress syndrome. N Engl J Med 2013;368:2159-68.

14. Zangrillo A, Biondi-Zoceai G, Landoni G, Frati G, Patroniti N, Pesenti A, et al. Extracorporeal membrane oxygenation (ECMO) in patients with H1N1 influenza infection: A systematic review and meta-analysis including 8 studies and 266 patients receiving ECMO. Crit Care 2013;17:R30.

15. Duggal A, Mireles-Cabodevila E, Krishnan S, Arroliga AC. Acute respiratory distress syndrome: Implications of recent studies. Cleve Clin J Med 2014;81:683-90.

16. Seretis C, Lagoudianakis E, Salemis N Pappas A, Gemenetzis G, Seretis F, et al. Liver biochemistry during the course of Influenza A/ H1N1 infection. Gastroenterol Res 2013;6:103-5.

17. Cunningham E, Kohli R, Venuto RC. Influenza-associated myoglobinuric renal failure. JAMA 1979;242:2428-9.

18. Pettilä V, Webb SA, Bailey M, Howe B, Seppelt IM, Bellomo R. Acute kidney injury in patients with influenza A (H1N1) 2009. Intensive Care 
Med 2011;37:763-7.

19. Wiesen J, Komara JJ, Walker E, Wiedemann HP, Guzman JA. Relative cost and outcomes in the intensive care unit of acute lung injury (ALI) due to pandemic influenza compared with other etiologies: A single-center study. Ann Intensive Care 2012;2:41.

20. Ranieri VM, Rubenfeld GD, Thompson BT, Ferguson ND, Caldwell E, Fan E, et al. Acute respiratory distress syndrome: The Berlin definition. JAMA 2013;307:2526-33.

21. Peek GJ, Mugford M, Tiruvoipati R, Wilson A, Allen E, Thalanany MM, et al. Efficacy and economic assessment of conventional ventilatory support versus extracorporeal membrane oxygenation for severe adult respiratory failure (CESAR): A multicentre randomised controlled trial. Lancet 2009;374:1351-63.

22. Phua J, Badia JR, Adhikari NK, Friedrich JO, Fowler RA, Singh JM, et al. Has mortality from acute respiratory distress syndrome decreased over time?: A systematic review. Am J Respir Crit Care Med 2009;179:220-7.

23. Brichon PY, Barnoud D, Pison C, Perez I, Guignier M. Double lung transplantation for adult respiratory distress syndrome after recombinant interleukin 2 . Chest 1993;104:609-10. 